\title{
Maria da Conceição Tavares
}

\author{
MARIA SILVIA POSSAS
}

$\mathrm{M}$ ARIA DA CONCEIÇÃo TAVARES, nascida em Portugal, foi uma das economistas de maior influência sobre o pensamento econômico brasileiro desde os anos 60, em especial o heterodoxo.

Após estudar matemática em Lisboa, veio para o Brasil onde se formou economista pela então Universidade do Brasil, hoje UFRJ. Trabalhou na CEPAL e tornou-se professora da UFRJ e, mais tarde, da Unicamp. Sua carreira acadêmica e sua obra sempre se pautaram por suas convicções éticas e políticas, de defesa de uma sociedade mais justa e solidária.

Seu espírito de luta acabou por levá-la a pleitear uma cadeira na Câmara de Deputados, mandato obtido e exercido de 1995 a 1999. Entretanto sentiu não ser ali que melhor poderia servir às suas idéias e voltou às lides acadêmicas após esse período.

Tornou-se célebre não só pelo vigor de seu pensamento, mas também pela paixão com que defende seus pontos de vista, sempre procurando identificar quais os interesses da grande maioria da população, excluída dos frutos do desenvolvimento, e tomar o seu partido (1).

Sua obra é bastante diversificada: escreveu artigos e livros influentes, tanto no campo teórico quanto acerca de aspectos variados da economia brasileira, o que torna mais difícil tratar em poucas páginas da autora, de suas obra e influência.

Seu primeiro trabalho relevante foi "Auge e declínio do processo de substituição de importações no Brasil”. Neste artigo já estavam presentes as questões que priorizaria mais adiante. A compreensão da dinâmica própria de economias como as latino-americanas, em particular a brasileira, foi o que o norteou: como se inserem essas economias no mercado internacional, como evolui sua distribuição de renda, como se dá o progresso técnico, como é possível financiar o investimento e o consumo, superando a precariedade dos sistemas financeiros locais, foram alguns dos problemas para cujo equacionamento procurou contribuir. Uma preocupação fundamental, característica de seu pensamento, já estava aí presente: a assimetria de poder existente entre as diversas economias.

Esses problemas voltaram a ser atacados em diferentes momentos de sua carreira e nortearam sua busca intelectual, pois poderiam ser a chave para uma defesa dos interesses dos excluídos e explorados. Profundamente interligados, tais problemas foram tratados tanto teórica quanto historicamente. Passemos a eles. 


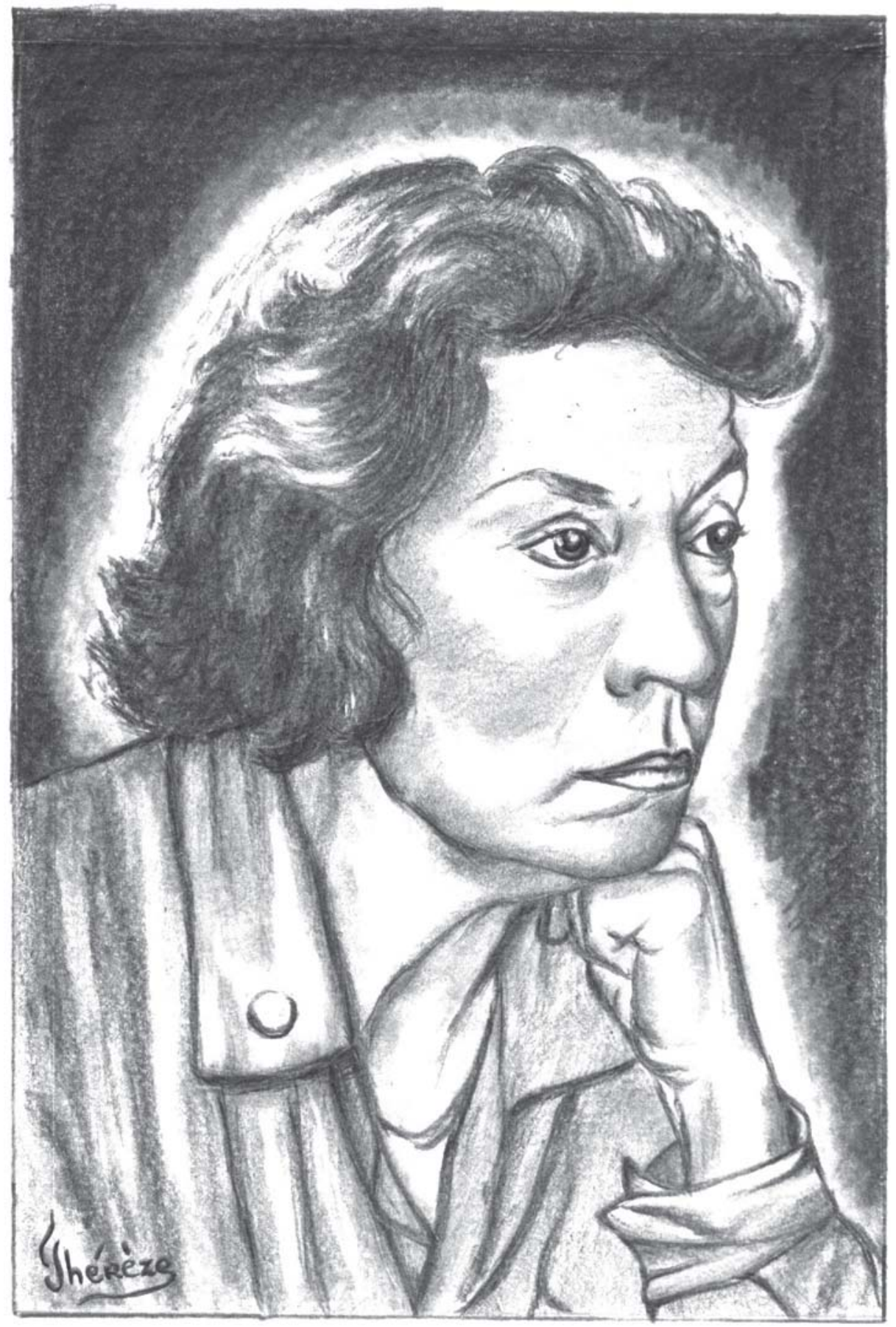

Maria da Conceição Tavares 


\section{Dinâmica da economia brasileira e articulação com distribuição de renda}

Seu primeiro trabalho influente, já citado, inseria-se na tradição cepalina e explicava o que foi o processo de substituição de importações, repensando-o, inclusive teoricamente. A interpretação da CEPAL tinha vários componentes importantes, que foram assumidos pela autora. Entre eles, a idéia de que o desenvolvimento não se dava em todos os lugares da mesma forma, seguindo as mesmas etapas. Uma vez que alguns países lograram se industrializar, a dinâmica de poder no conjunto da economia mundial relegava os demais a um papel dependente e periférico (2).

Este era o caso dos países latino-americanos. Suas economias teriam passado por uma fase primário-exportadora, caracterizada pelo chamado "crescimento para fora", seguida por uma "substituição de importações". Durante aquela primeira etapa, a dinâmica interna das economias teria estado subordinada ao desempenho das exportações de produtos primários. Os óbices às exportações oriundos de fatos como guerras ou depressões levaram esses países a buscar o mercado interno, procurando produzir domesticamente bens outrora importados.

Conceição Tavares retomou essa interpretação, procurando entender melhor a dinâmica de tais economias. No período do crescimento para fora, essas economias apresentavam um aspecto dual: de um lado, um setor exportador, de alta rentabilidade; de outro, um setor voltado ao mercado interno, de baixa produtividade, satisfazendo apenas em parte as necessidades básicas, que dependiam também de elevadas importações. Alta concentração da propriedade era acompanhada de extrema desigualdade na distribuição de renda, permitindo às elites um padrão de consumo semelhante ao dos grandes centros desenvolvidos. Uma característica importante desse modelo é que o principal componente autônomo de demanda era a exportação. Por conseguinte, o dinamismo da economia era totalmente subordinado ao exterior.

Esse modelo foi quebrado pelas sucessivas crises no comércio externo que começaram na Primeira Guerra, agravaram-se com a Grande Depressão e continuaram a renovar-se. Essas crises impediam que as necessidades até então supridas pelas importações fossem satisfeitas. Mediante mecanismos e estímulos variados, que incluíam controles de câmbio e de importações, iniciaram-se tentativas de produzir internamente o que vinha sendo importado, na chamada substituição de importações. Tratava-se de um novo modelo de crescimento, com uma dinâmica distinta do anterior.

O setor produtivo modificava-se, com uma industrialização baseada em sucessivas ondas de implantação de elos cada vez mais à montante da cadeia produtiva. Essas mudanças ocorreram principalmente na indústria, não sendo muito alteradas as condições da agricultura, inclusive a exportadora. Assim, o 
dualismo da economia não foi superado, a base exportadora permaneceu frágil: de fonte de dinamismo, passou a desempenhar o papel de restrição ao crescimento pois, mesmo para realizar a substituição de importações, era necessário dar continuidade à importação dos bens intermediários e de capital imprescindíveis para implementar e ampliar novas fábricas e linhas de produção. No processo ocorria uma modificação da pauta de importações - relativamente menos bens de consumo e mais insumos e equipamentos. Tal mudança era obtida não apenas pela via do mercado, mas também por inúmeros mecanismos de compressão das importações menos essenciais.

O processo avançava via respostas às sucessivas barreiras que se colocavam às importações, porém a superação desses obstáculos se tornava cada vez mais árdua. As razões para tanto eram variadas: tecnologia, dimensão e estrutura do mercado interno, o qual podia não comportar grandes escalas; dificuldade para prosseguir modificando a pauta de importações, uma vez que o processo continuava a exigir importações dos bens necessários à produção dos substitutos das importações anteriores. Esses obstáculos acabaram por levar ao esgotamento do processo, que, porém, foi diferente nos diversos países. O Brasil, pelo seu tamanho, foi um dos poucos a conseguir avançar até a implantação de partes do setor de bens de produção, os quais necessitavam investimentos vultosos.

A péssima distribuição de renda, segundo a visão cepalina e a da autora, fazia com que apenas poucas pessoas tivessem acesso ao consumo. Os mercados eram relativamente pequenos. As novas indústrias já nasciam concentradas. A tecnologia utilizada, importada das economias mais desenvolvidas, exigia grandes escalas, o que colocava problemas pelo lado do financiamento e não se adequava à constelação dos recursos internos - abundante mão-de-obra pouco qualificada, mas capital e mão-de-obra qualificada escassos. O processo resultante desse modelo de desenvolvimento poderia ainda ser mais concentrador de renda.

Ao fim da década de 60 outro artigo marcante foi escrito por ela, desta feita em co-autoria com José Serra: "Além da estagnação". Na ocasião predominava na CEPAL a visão - expressa por Celso Furtado, por exemplo - de que as economias da América Latina, em especial a brasileira, apresentavam uma tendência à estagnação. Esta, associada ao fim do dinamismo do processo de substituição de importações, decorreria da incompatibilidade entre o padrão de distribuição de renda e as tecnologias usadas. O primeiro limitava o tamanho do mercado; as últimas exigiam grandes escalas de produção, enorme aporte de capital e pouca utilização de mão-de-obra não-qualificada, favorecendo, portanto, a concentração da renda ainda maior. É a crítica a esta interpretação o objeto do referido artigo.

Nele, os autores alegavam que o declínio das taxas de crescimento da economia brasileira na ocasião não representava uma tendência persistente à estagnação, mas apenas uma crise episódica, que poderia ser superada. Criticavam 
a argumentação de Furtado no sentido de que o aumento da relação capitaltrabalho levaria a um declínio da taxa de lucro e, conseqüentemente, da acumulação. Alegavam que o aumento da produtividade do trabalho e o favorecimento dos lucros em detrimento dos salários poderiam evitar aquele declínio. Isso poderia redundar eventualmente em um processo de crescimento injusto. O processo de substituição de importações realmente encontrara seu limite e o "Plano de Metas", programa econômico levado a cabo por Juscelino Kubitschek, teria tido papel semelhante a uma onda de inovações schumpeteriana, encontrando também um limite. Mas o declínio posterior do crescimento não tinha característica de uma tendência secular e sim de uma baixa cíclica, que poderia ser combatida.

A não-ocorrência da estagnação não significava porém um diagnóstico dos mais positivos. A crise anterior de meados dos anos 60 teria sido a transição a um novo estilo de desenvolvimento, com novo esquema de concentração do poder e nova inserção internacional. O declínio das taxas de crescimento do PIB não teria significado ausência de "expansão", como definiram os autores, pois esta poderia também se dar mesmo sem crescimento, quando houvesse uma reordenação da economia, com o surgimento de novas atividades dinâmicas.

No modelo de desenvolvimento que então se esboçava, Estado e capital estrangeiro seriam os principais agentes, associados a novas formas de acumulação de capital, mais propriamente financeiras. O esquema dual anterior, no qual havia um setor atrasado voltado ao mercado interno e um mais dinâmico ligado às exportações, também foi modificado. Não que o progresso técnico se generalizasse por todo o sistema, mas houve uma certa integração mais global do sistema, pela penetração dos meios de transporte e comunicação. A heterogeneidade, porém, não foi eliminada e continuou se aprofundando, com uma contínua alteração de quais atividades acompanhariam a modernização. A expansão não foi de molde a absorver ou liquidar atividades tradicionais nem a integrar a mão-de-obra delas proveniente. A exclusão social foi reposta.

Com relação à renda pessoal, ocorreu uma tendência à sua permanente redistribuição ou reconcentração, através da qual se compatibilizou a geração de excedente necessário e a expansão dos mercados. Isso se manifestou, por exemplo, na abertura do leque de salários.

O tema da dinâmica da industrialização brasileira foi retomado e aprofundado num importante trabalho da década de 70, Acumulação de capital e industrialização no Brasil, no qual foi feita uma releitura de diversos autores, entre eles Marx, Keynes, Schumpeter, Kalecki e Steindl, procurando montar modelos de "padrões de acumulação". Estes padrões representavam formas alternativas de crescimento, que compatibilizariam taxas diferenciadas de crescimento dos diversos setores da economia e formas de competição neles vigentes com uma distribuição de renda particular. 
Com João Manuel Cardoso de Melo, criou o conceito de industrialização retardatária, como uma alternativa à visão cepalina e às teorias da dependência para a interpretação do caso brasileiro e de outros semelhantes. Por esse conceito, a idéia de industrialização deveria ser vista, não simplesmente como implantação ou crescimento da indústria, mas como a instalação de um núcleo de setor de bens de produção, especialmente bens de capital, que permitiriam internalizar, ao menos em parte, os principais determinantes da dinâmica econômica: o investimento e o progresso técnico. Tratava-se da "constituição de forças produtivas especificamente capitalistas". Se não houvesse produção interna de bens de capital, os efeitos multiplicadores do investimento seriam exportados e a economia se manteria mais dependente do comércio exterior também para a introdução de inovações. Mas, uma vez ocorrida a industrialização, a dinâmica econômica não poderia ser considerada reflexa. O outro ponto importante do conceito de industrialização retardatária era que apontava para o momento em que esta ocorria, ocasião em que, no plano mundial, em vários setores fundamentais, inclusive de bens de produção, predominavam escalas de produção elevadas e estruturas de mercado oligopolizadas. Tais aspectos colocavam problemas quanto à centralização dos capitais necessários, à obtenção de tecnologia, à concentração dos mercados. Essa industrialização não poderia se fazer sem o concurso do Estado, articulando os interesses e atraindo o capital necessário, inclusive estrangeiro.

Embora desde os anos 30 houvesse a implantação de algumas empresas de bens de produção - menos de bens de capital e mais de bens intermediários -, a industrialização permaneceu "restringida", até a implantação do Plano de Metas. Pois "o desenvolvimento das forças produtivas e os suportes internos da acumulação urbana são insuficientes para implantar a grande indústria de base necessária ao crescimento da capacidade produtiva adiante da própria demanda" (3). Para a implantação de um departamento de bens de produção significativo seria necessária a ocorrência de um bloco de investimentos complementares, com caráter concentrado no tempo.

Por essa abordagem, a interpretação anterior do processo de substituição de importações foi revista, os determinantes oriundos dos estrangulamentos externos considerados menos relevantes e conferido maior peso à dinâmica endógena da acumulação de capital. Construindo um novo aparato teórico, no qual uniu determinantes relativos às formas de concorrência (que apontavam para a microdinâmica) e às categorias de uso dos bens (ligados à macrodinâmica), procurou examinar o ciclo iniciado com o Plano de Metas, o desequilíbrio setorial do processo aí desencadeado e como seria difícil manter as altas taxas de crescimento naquelas circunstâncias.

Em um trabalho posterior, o período de 1966 a 1974 foi analisado com a utilização e aperfeiçoamento do mesmo instrumental (4). 


\section{Particularidades do sistema financeiro no Brasil}

Outra preocupação recorrente na obra de Conceição Tavares relacionava-se com os problemas do financiamento na economia brasileira e como se articulavam ao funcionamento do capital financeiro internacional.

Como já foi levantado, a industrialização retardatária brasileira (e latinoamericana) colocou enormes problemas de financiamento. As escalas de produção nos setores que estavam sendo implantados eram muito grandes. O sistema financeiro brasileiro, criado para financiar o café, não era adequado para essa tarefa. As características desse sistema financeiro, as modificações implementadas durante a reforma Campos-Bulhões - de 1964 a 1968 - e os problemas remanescentes foram tratados em diversos artigos e ensaios. Aqui, vou me restringir principalmente ao que foi discutido em Ciclo e crise: o movimento recente da industrialização brasileira.

No primeiro capítulo desse trabalho, essencialmente teórico, a autora já chamava a atenção para um ponto que muitas vezes seria retomado por ela e por seus discípulos: a noção (keynesiana) de poupança. O conceito que importava não era o de uma poupança desejada, mas o de poupança potencial - ou seja, a renda não consumida. Isso era importante do ponto de vista da análise da dinâmica econômica centrada na demanda efetiva.

No que tangia ao financiamento do investimento, não havia por que se recorrer a qualquer conceito de poupança. Aí o que interessava era o funcionamento de um sistema financeiro capaz de centralizar recursos, ativos e passivos financeiros, não-oriundos da poupança corrente, isto é, da ausência de consumo corrente.

Chamava a atenção para as inúmeras possibilidades de valorização contábil "fictícia" de parte do capital assim aplicado, que faziam com que numa economia avançada os ativos financeiros superassem de longe o valor dos ativos reais. Só uma parte dessa valorização, correspondente à dívida primária nova, financiaria a economia real e receberia os juros por esta pagos (o que só ocorreria após a maturação do investimento). O restante dos juros, os derivados da circulação financeira, corresponderia a uma redistribuição entre os capitalistas dos lucros obtidos pelo conjunto do capital financeiro.

Isso abria espaço para a crise de crédito. Se o investimento caísse, os lucros também se reduziriam, ficaria difícil remunerar os juros das dívidas primárias, e com elas de todas as demais, deprimindo ainda mais o movimento do capital produtivo.

No caso brasileiro, tratado no último capítulo do livro, as estruturas institucional e do sistema de financiamento da década de 1950 eram inadequadas para financiar a expansão dos novos setores. A partir de 1964 houve a reforma do sistema monetário, e de 1965 a do sistema financeiro. Novos instrumentos e instituições foram criados, entre eles a correção monetária, as cadernetas de 
poupança, as letras de câmbio, o BNH (Banco Nacional de Habitação). Esses instrumentos foram capazes de fazer com que, naquele momento, o sistema financeiro privado brasileiro cumprisse algumas funções de seus congêneres dos países desenvolvidos: criar crédito ampliado; intermediar a transferência de capital de empréstimo; valorizar o capital no circuito financeiro, mas deixaram de direcionar e de dar suporte à acumulação, especialmente de financiar projetos de grande porte e longos prazos de maturação. Esta função foi remetida ao Estado e às suas agências financeiras, mas cumprida de modo diferente, pois o Estado não agia como capital financeiro autônomo, promovendo fusões e conglomerações sob seu comando. Não havia, pois, a constituição efetiva do capital financeiro como sujeito do processo de centralização do capital.

Outro desdobramento das reformas bancária e financeira apontado por Conceição Tavares foi o estabelecimento de duas formas de dinheiro: de um lado, papel moeda e depósitos à vista e, de outro, o dinheiro financeiro, corrigido monetariamente. A primeira era meio de circulação. A outra, que criou unidade de conta própria, a UPC (unidade padrão de capital), assumia a função de reserva de valor e instrumento de valorização do capital-dinheiro.

Este fenômeno tornou-se mais nítido com o modo de operação do open market a partir de meados da década de 70 , garantindo liquidez aos aplicadores, com a utilização das cartas de recompra. Conceição Tavares demonstrou como se formou a chamada ciranda financeira. O crescimento da dívida externa traduziase em grande entrada de divisas, que deveriam ser convertidas em cruzeiros. Para evitar a emissão de moeda, o Banco Central vendia títulos públicos, comprometendo-se a recomprá-los a qualquer momento, fazendo, dessa forma, que adquirissem liquidez. Esse mecanismo servia para alimentar a inflação. Dívidas interna e externa estavam, portanto, inteiramente acopladas.

A inflação voltou a ser tratada em outro artigo importante, em co-autoria com Luiz Gonzaga Belluzzo. Criticando a visão de expectativas racionais e a de inflação inercial, julgavam que o papel crucial na aceleração da inflação era cumprido por expectativas quanto aos juros, de caráter mais especulativo.

Essas foram algumas das contribuições da autora no sentido de uma abordagem mais integrada entre moeda, finanças e economia "real", todas sob a égide dos movimentos especulativos do capital financeiro e de suas particularidades no Brasil.

\section{Os EUA e a ordem mundial}

Para Conceição Tavares, economia e poder não constituíam fatos que pudessem ser analisados de modo isolado. Em cada um de seus trabalhos a questão do poder esteve presente, inclusive no que tange às relações entre economias nacionais. Este ponto, já abordado na noção de centro-periferia da CEPAL, assumiu um papel central em sua obra a partir do artigo "A retomada da hegemonia 
norte-americana" (5). Nesse trabalho ela propôs que a política econômica norteamericana do início dos anos 80 , a qual teve, entre outras conseqüências, fazer com que os EUA passassem de país credor à posição de maior devedor do mundo em poucos anos e que o déficit do balanço comercial norte-americano se multiplicasse entre 1982 e 1984, chegando a incríveis US\$ 120 bilhões, longe de significar perda do poderio econômico daquele país, na verdade era parte de um movimento de retomada de sua hegemonia. Os Estados Unidos naquele momento viam sua liderança tecnológica perder o vigor, mas sua hegemonia não se fundava apenas nesse aspecto. Tratava-se - e ainda se trata - do país emissor da principal moeda, por assim dizer a moeda mundial e, além disso, com indiscutível domínio bélico. Com um PIB enorme, cuja dinâmica própria repercutia em todo o resto da economia mundial de modo importante, senhor do dinheiro e da guerra, aquele país conseguiu impor ao resto do mundo os seus interesses. Mas a hegemonia não era apenas bélica e econômica, traduzindo-se também na capacidade de compelir "seus sócios ou rivais capitalistas (...) não apenas a submeter-se, mas a racionalizar a visão dominante como a 'única possível' " (6), ou seja, com uma face também político-ideológica.

Segundo a autora, no fim dos anos 70 o poderio norte-americano parecia perder importância. Alemanha e Japão eram potências econômicas emergentes, que não se poderia prever pudessem ser enquadradas pelos EUA, e o dólar uma moeda que se enfraquecia. Em 1979 o primeiro passo da retomada da hegemonia foi aplicado quando Paul Volcker, então presidente do Federal Reserve, impôs um dólar forte ao resto do mundo, contra a posição do FMI e da maioria dos países membros, mediante um aumento sem precedentes da taxa de juros norteamericana, que chegou a um teto de $20 \%$ ao ano. Essa política mergulhou o mundo numa recessão, inclusive quebrando empresas e bancos norte-americanos. Permitiu, contudo, que o FED retomasse o controle dos bancos em seu território e do resto do sistema bancário mundial, tomando as rédeas da situação.

Após os primeiros episódios de dificuldades de países periféricos endividados, o "sistema de crédito interbancário orientou-se decisivamente para os EUA e o sistema bancário passou a ficar sob o controle da política monetária do FED” (7). Todos os grandes bancos passaram a financiar o déficit fiscal norte-americano. Não apenas eles se submeteram, mas também todas as demais economias, importantes ou não, foram forçadas a se alinhar aos interesses dos EUA, a despeito de suas tentativas de resistência. Suas políticas monetária, fiscal, de câmbio e de taxas de juros tinham que se adequar à norte-americana, devido à dolarização generalizada do sistema de crédito.

Esse movimento não implicou que todos os aspectos particulares da política então iniciada devessem ser mantidos. Ao contrário, após algum tempo o dólar voltou a cair e a economia norte-americana a crescer. O movimento de alinhamento e submissão de seus parceiros já havia sido feito. 
Anos depois, a autora reiterou suas posições. Agora parecia mais claro que os EUA se mantinham de fato como país dominante e que sua hegemonia parecia bem longe de ser desafiada. Em 1997, num artigo que procurava reavaliar o anterior (8), ela considerava que "a concentração de poder político e financeiro existente no mundo contemporâneo não é o resultado espontâneo do aumento da competição e da eficiência dos 'mercados globalizados', mas de uma política deliberada de retomada da hegemonia mundial". Mas a situação daí oriunda, além de não estar consolidada, certamente não deveria ser considerada benéfica para todos. Ao contrário, nela imperavam a assimetria e a exclusão.

O processo de crescimento dos últimos 15 anos, alegavam os autores, teve um caráter concentrador, baseado num regime de acumulação, caracterizado por três aspectos: acirramento da concorrência, marcado pela destruição e rápida deslocalização das atividades produtivas, com rápidas mudanças das vantagens comparativas dinâmicas; concentração de capitais, com aumento de importância de fusões e aquisições; centralização de capital no plano mundial, com direcionamento dos fluxos de capital financeiro e da disponibilidade de liquidez sujeitos a uma lógica financeira unificada - a chamada globalização financeira.

A partir dessa visão do rearranjo do poder econômico-financeiro global, ela estudou os ajustes forçados de economias desenvolvidas, bem como a situação e possibilidades de ação do Brasil, quando comparado a México e Chile, no livro (Des)ajuste global e modernização conservadora.

Segundo a autora, apesar de a gravidade dos diagnósticos, ainda mantinhase viva uma tênue chama de esperança, pois a "própria universalização de condições duras de exclusão torna-as de difícil sustentação e propicia a ocorrência de transformações sociais profundas que terminam por alterar a doutrina e a própria ordem hegemônica" (9).

\section{Notas}

1 Não estou com isso avalizando ou não suas posições, mas apenas procurando informar sobre as características do estilo dessa autora, tanto em sua obra quanto em aulas, palestras, seminários etc.

2 Evidentemente essa é uma descrição muito esquemática. Quero apenas salientar que para todos os autores dessa tradição, a avaliação das condições de superação do subdesenvolvimento implica entender a economia mundial como um conjunto e levar em conta as relações de poder (econômico, tecnológico, financeiro) aí estabelecidas.

3 Sobre o assunto, veja-se Tavares, Maria Conceição, Acumulação de capital e industrialização no Brasil, Campinas, Editora da Unicamp, 1986, p.103.

4 Id., Ciclo e crise: o movimento recente da industrialização brasileira, tese para concurso de professor titular da UFRJ, Rio de Janeiro, mimeo, cap. III. Em 1998 esse trabalho foi publicado pelo Instituto de Economia da Unicamp. 
5 A primeira versão desse artigo foi publicada pela Revista de Economia Política 18, v. 5, n. 2, abr./jun. 1985. Uma versão mais completa encontra-se em Tavares, M.C. \& Fiori, J.L. (org.) Poder e dinheiro. Rio de Janeiro, Zahar, 1997.

6 Cf. Tavares, M.C. \& Fiori, J.L. (org.) Poder e dinheiro, cit., p. 29.

7 Id. ibid., p.34.

8 Ver, de Tavares, M.C. \& Melin, L.C., Pós-escrito 1997: a reafirmação da hegemonia norte-americana, in Poder e dinheiro, cit., p. 55-86.

9 Id. ibid., p.80.

\section{Referências bibliográficas}

TAVARES, Maria da Conceição. Da substituição de importações ao capitalismo financeiro. Rio de Janeiro, Zahar, 1972 (Fazem parte desse livro os artigos: Auge e declínio do processo de substituição de importações no Brasil; Notas sobre o problema do financiamento numa economia em desenvolvimento - o caso do Brasil; Além da estagnação; Natureza e contradições do desenvolvimento financeiro recente).

. Acumulação de capitale industrialização no Brasil. Campinas, Editora

da Unicamp, 1986. Republicada em 1998 pelo Instituto de Economia da Unicamp.

Ciclo e crise: o movimento recente da industrialização brasileira. Campinas, Instituto de Economia, 1998.

TAVAReS, Maria da Conceição e FIORI, José Luís (org.) Poder e dinheiro. Petrópolis, Vozes, 1997 (Destacam-se seus artigos: A retomada da hegemonia norte-americana e, em co-autoria com Luiz Eduardo Melin, Pós-escrito 1997: a reafirmação da hegemonia norte-americana).

e Terra, 1993.

(Des)ajuste global e modernização conservadora. Rio de Janeiro, Paz

TAVARES, Maria da Conceição e BELLUZZO, Luiz Gonzaga. Uma reflexão sobre a natureza da inflação contemporânea. In: Rego, José Márcio (org.). Inflação inercial, teorias sobre inflação e o Plano Cruzado. Rio de Janeiro, Paz e Terra, 1986.

RESUMO - MARIA da Conceição Tavares exerceu grande influência sobre o pensamento econômico brasileiro. Tratou de assuntos variados, mas há uma preocupação que perpassa toda a sua obra: o desenvolvimento de países "periféricos" (com especial ênfase no caso brasileiro) e a sorte de grandes contingentes da sua população, excluídos economicamente. Seu ponto de partida foi o pensamento cepalino, com ênfase nas relações econômicas e de poder entre nações centrais e periféricas. Porém procurou repensar essa matriz, ampliando a importância de questões como: variáveis internas a cada país, em especial a 
presença do setor produtor de bens de capital; as necessidades de financiamento do desenvolvimento e como os modos historicamente específicos de atendê-las repercutem.

ABSTRACT - MARIA da Conceição Tavares has had a great influence on Brazilian economic thought. Among the various subjects she treated, there has been a major concern present in all her work, namely, the development of "peripheral" countries (especially Brazil) and the fate of large contingents of its peoples that are economically excluded. Her theoretical matrix was the ideas originated in ECLA, which emphasized power and economic relations among "central" and "peripheral" nations. She tried to rebuild this matrix, augmenting the importance of questions such as: variables that were internal to each country, specially the presence of a capital goods department; the need of funds to finance development and the consequences of the historical specific institutions and ways used to provide them.

Maria Silvia Possas é professora doutora de Economia na UFRJ. Sua formação acadêmica foi toda realizada na Unicamp, onde teve estreito contato com a visão de Maria da Conceição Tavares, que a orientou em sua dissertação de mestrado. 